\title{
Focus on therapy of primary stabbing headache
}

\author{
Enrico Ferrante $\cdot$ Paolo Rossi $\cdot$ Cristina Tassorelli \\ Carlo Lisotto · Giuseppe Nappi
}

Received: 3 December 2009/Accepted: 7 January 2010/Published online: 30 January 2010

(C) Springer-Verlag 2010

\begin{abstract}
Primary stabbing headache (PSH) is a shortlasting but troublesome headache disorder, which has been known for several decades. The head pain occurs as a single stab or as a series of stabs generally involving the area supplied by the first division of trigeminal nerve. Stabs last for approximately a few seconds, occurring and recurring from once to multiple times per day in an irregular pattern. For the diagnosis of PSH, it is mandatory that any other underlying disorder is ruled out. Indomethacin represents the principal option in the treatment of PSH, despite therapeutic failure in up to $35 \%$ of the cases. Recent reports showed that cyclooxygenase-2 (COX-2) inhibitors, gabapentin, nifedipine, paracetamol and melatonin may also be effective. In this report, we focus on the therapy of PSH summarizing the information collected from a systematic analysis of the international literature over the period 1980-2009.
\end{abstract}

\footnotetext{
E. Ferrante

Department of Neuroscience,

Niguarda Ca' Granda Hospital, Milan, Italy

P. Rossi

Headache Clinic INI Grottaferrata, Rome, Italy

C. Tassorelli $(\bowtie) \cdot$ G. Nappi

Headache Science Centre,

IRCCS "Neurological Institute C. Mondino" Foundation,

University Centre for Headache and Adaptive Disorders

(UCADH), University of Pavia, Pavia, Italy

e-mail: cristina.tassorelli@mondino.it

C. Lisotto

Department of Neuroscience, Headache Centre,

S. Vito al Tagliamento Hospital, Pordenone, Italy

G. Nappi

Chair of Neurology, University "La Sapienza", Rome, Italy
}

Keywords Primary stabbing headache - Therapy · Indomethacin · COX-2 inhibitors · Gabapentin . Melatonin

\section{Background}

Primary stabbing headache (PSH) is a disorder first described by Lasche in 1964 as "ophthalmodynia periodica" [1]. This was followed, in 1979, by the term "jabs and jolts syndrome" which, coined by Sjaastad et al. [2] was inspired by the patients' own descriptions of their complaint: they reported either short-lasting head pains ("jabs"), or severe shock-like head pains, even accompanied by head movement ("jolts"). Raskin and Schwartz later reported "ice pick-like headache" in migraine sufferers [3]. Terms, such as "needle-in-the-eye-syndrome" and "sharp, short-lived head pain syndrome" [4] have also been used.

The second edition of the International Classification of Headache Disorders (ICHD II-2004) has proposed diagnostic criteria for PHS (code 4.1) (Table 1) [5].

The exact prevalence of PHS in the general population has not been established. According to some authors, it is $2 \%$ [6], while in an epidemiological study conducted in the Norwegian population; it was reported to be $35.2 \%$ [7]. The average age at onset is variable, ranging from 28 [7] to 47 years [8] (range 12-70 years). Women are more affected than men [9].

PSH can occur as an isolated headache or in association with other headache syndromes $[4,10]$, such as migraine, in up to $63 \%$ [11], tension-type headache in up to $27.3 \%$ [11], cluster headache (in about 30\%) [12], chronic paroxysmal hemicrania, hemicrania continua, and cervicogenic headache. 
Table 1 Types and subtypes of other primary headaches

Other primary headaches
Primary stabbing headache
Primary cough headache
Primary exertional headache
Primary headache associated with sexual activity
Preorgasmic headache
Orgasmic headache
Hypnic headache
Primary thunderclap headache
Hemicrania continua
New daily persistent headache (NDPH)

From reference (5)

When PSH and migraine attacks appeared simultaneously, they frequently did so in the same region. In the group of patients in which they occur with other type of headaches, both appeared in the same area as well as in the different areas [8].

Head pain occurring as a single stab or a series of stabs of short duration $(<3 \mathrm{~s})$, of variable intensity, is located exclusively or predominantly in the distribution of the first branch of the trigeminal nerve (orbit, temporal and parietal area).

In some studies, the head pain frequently involved extratrigeminal regions (70\%): auricular, posterior parietal, occipital, and nuchal areas [13]. Attacks of PSH vary greatly in frequency (from 1 attack per year to 50 attacks per day) and show a rather unpredictable long-term pattern [4].

Because the frequency of occurrence is low in most cases, patients rarely consult their doctor for this type of headache.

The paroxysms occur at random throughout the day. In rare cases, stabs occur repetitively over days, and there has been one description of a paroxysmal state lasting a week. Some people report the persistence, lasting minutes or hours after a particularly intense stab, of a mild, dull pain in that same area. The pain is not associated with other symptoms or objective signs.

Although the mechanism of PHS is unknown, the source of irritation might be in the peripheral branches of the trigeminal or other nerves; however, it seems more likely that there is an intermittent deficit in central pain control mechanisms that permits the spontaneous synchronous discharge of neurons receiving impulses from the area to which stabbing pain is referred [14].

\section{Treatment}

In the following paragraphs, we summarize the information collected from a systematic analysis of the international literature. We conducted a baseline literature search of the period 1980-2009, employing available electronic databases (National Library of Medicine, National Institute of Health, Embase) with the following medical search terms: jabs and jolts syndrome or headache/ice-pick and headache or pain/stabbing headache. Whenever available, chapters of book were also consulted and considered.

PSH is considered to be one of the indomethacinresponsive headaches $[8,15]$.

It is not known why indomethacin is effective, but it must exert its effect differently than other non-steroidal anti-inflammatory drugs. Unique properties of indomethacin include the ability to reduce cerebral blood flow and decrease cerebrospinal fluid pressure [16]. Furthermore, it is postulated that it exerts antagonistic effects in the nitric oxide pathways [17]. Like other NSAIDs, indomethacin is a potent reversible inhibitor of prostaglandin-forming cyclooxygenase (COX). It also inhibits phosphodiesterase, thereby increasing intracellular cyclic adenosine monophosphate levels [18].

Mathew [4] reported a clinical recovery in five patients treated with indomethacin $50 \mathrm{mg}$, three times a day. Conversely, Sjaastad [19] found little clinical response to treatment with indomethacin.

Pareja [8] described 17 cases treated with indomethacin at a dosage of $75 \mathrm{mg}$ daily for 15 days, which resulted in complete improvement in $6(35 \%)$, partial improvement in $5(30 \%)$ and no benefit in $6(35 \%)$. He pointed out the considerable difficulty evaluating the effect of the drug in $\mathrm{PSH}$, given the marked and spontaneous variation in attack frequency. Fuh et al. [13] described 65 patients treated with indomethacin (46 cases) and rofecoxib (19 cases). The mean dosage of indomethacin $(25 \mathrm{mg}$ bid or tid) was $59 \pm 16 \mathrm{mg}$, while rofecoxib was administered in a dosage of $50 \mathrm{mg} / \mathrm{day} ; 33$ (51\%) patients had a complete remission and $19(22 \%)$ showed a partial response. The remission rate (at least 50\% improvement) did not differ between patients who received indomethacin and those given rofecoxib (74 vs. $68 \%, P=0.2$ ). Four patients discontinued indomethacin during the 2-week treatment period: one was allergic to indomethacin and three complained of gastrointestinal upset. The findings of this study, in terms of the preventive efficacy of the treatment, may not be reliable given that it involved patients with a low frequency of attacks and recorded only 2-week response. Martins [20] reported three patients with extra-trigeminal ice-pickstatus responding promptly to indomethacin (dosage was not reported).

More than $35 \%$ of patients receiving therapeutic dosages of indomethacin experience adverse effects and approximately $20 \%$ have to discontinue the drug. Many people cannot tolerate long-term indomethacin therapy because of its gastrointestinal or renal side effects or because they 
have contraindications to indomethacin (e.g. they are on anticoagulation therapy).

Patients who cannot tolerate indomethacin represent a challenge as regards the management of PSH. However, anecdotal observations suggest that drugs other than indomethacin may be helpful in treating PSH.

Piovesan et al. [11] reported three elderly patients presenting PSH within 20 days of stroke onset and responding to celecoxib (100 mg bid), a COX-2 specific inhibitor (full recovery from $\mathrm{PSH}$ within 6 days of first administration of the drug). Interruption of the drug after 60 days' treatment with celecoxib induced the reappearance of painful symptoms in two patients. Celecoxib was reintroduced and there was no recurrence of the symptoms. One of these two patients died of cardiac arrest during a coronary bypass procedure, while the other patient was followed-up for 120 days and did not show any further recurrence of the pain. A second interruption of celecoxib did not cause the headaches to recur.

O' Connor et al. [21] described one case responding to etoricoxib (60 mg once daily with food), a selective COX-2 inhibitor. The patient reported a major improvement in symptoms within days (full recovery within a week); 9 months post-commencement, the patient was still asymptomatic.

COX-2 is a key enzyme in conversion of arachidonic acid to prostaglandins and thromboxanes, and is a target enzyme for non-steroidal anti-inflammatory drugs. It is normally expressed throughout the brain in discrete populations of neurons and is regulated by glutamate receptors and glucocorticoids. Recently, seizure and brain ischemia were reported to induce COX-2 mRNA or protein. COX-2 is induced within hours after neuronal spreading depression and transient focal ischemia in perifocal cortical neurons by a mechanism-dependent NMDA receptors.

In the nervous system, $\mathrm{COX}-2$ can play roles in the regulation of cerebral blood flow, fever, hypothalamic control of the stress response, the sleep/wake cycle, and in peripheral and central control of pain perception [22]. COX-2 mRNA could be detected in dentate gyrus cells, pyramidal cell neurones in the hippocampus (CA4-CA1), the piriform cortex, superficial cell layers (II and III) of the neocortex, the amygdala, and at low levels in the striatum, thalamus (subparafascicular nucleus) and hypothalamus (paraventricular and median preoptic nuclei), nucleus of the optic tract, the pontine reticular formation and the dorsal raphe nucleus [23]. COX-2 inhibitor could attenuate the neuronal spreading depression that occurs in seizures as well as NMDA-mediated nociceptive excitotoxicity [24].

NMDA receptors play a role in nociceptor. Activation of NMDA receptors causes the spinal cord neuron to become more responsive to inputs, resulting in central sensitization. Competitive and non-competitive NMDA receptor antagonists inhibit the response of dorsal horn nociceptive neurons to noxious stimulation and attenuate hyperalgesic behaviors in a variety of models [25].

The response of PSH to the use of selective COX-2 inhibitors is in line with previous reports of their use in other types of indomethacin-responsive headache. This fact, together with the low side-effect profile of this class of drug, makes selective COX-2 inhibitors a safe therapeutic option in this type of headache [26, 27]. Furthermore, the long-term use of indomethacin in the elderly has been reported to be associated with a greater risk of fatal adverse events, such as bleeding or perforation of a gastric ulcer, and bone marrow depression or leukemia [28], while celecoxib shows good tolerability and safety [8]. The COX-2 inhibitors, because of their lower side-effect profile, might be suitable for patients with contraindications to indomethacin, although their long-term use has recently been associated with an increased risk of myocardial infarction and stroke, and rofecoxib has been withdrawn from the market worldwide [29]. The long-term safety of COX-2 inhibitors is still under investigation [30].

Fusco et al. [31] described 12 children and adolescents with PSH who showed a good response when treated with paracetamol (dosage not reported).

Franca et al. [17] described four cases with PSH responding to gabapentin $(400 \mathrm{mg}$ bid). The patients became asymptomatic within a few days (from 3 to 15 days) of commencing therapy. The treatment was continued for 6 months ( 3 cases), after which it was stopped without a return of the symptoms. These four patients had previously been treated with indomethacin $50 \mathrm{mg}$ tid for 10 days and were subsequently treated with rofecoxib $25 \mathrm{mg}$ bid for 10 days, in both cases without improvement.

Jacome [32] described one patient responding to slowrelease nifedipine $(90 \mathrm{mg} /$ day $)$. The patient remained asymptomatic over a 3-year follow-up.

In a study by Rozen [33], melatonin, on the strength of its structural similarities to indomethacin and its possible pain-relieving properties, was administered to three patients with PSH to assess its effectiveness. All of the reported patients had shown a positive response to indomethacin. The three patients were given different dosages of melatonin (respectively 3, 9 and $12 \mathrm{mg}$ ). All the patients became asymptomatic and remained so throughout a 2- to 4-month follow-up. Melatonin is a pineal hormone and marker of circadian function. Its chemical structure is very similar to that of indomethacin. It has shown antinociceptive and antiinflammatory properties in animal studies and enhances the antiinflammatory effects of indomethacin in these same animal models [34]. Melatonin appears to be an effective alternative treatment for PSH.

In conclusion, $\mathrm{PSH}$ is one of the indomethacin-responsive headache syndromes. For individuals who have a 
contraindication to indomethacin, very few alternatives are available. COX-2 inhibitors have shown efficacy in some patients, but they have many of the same patients' contraindications as indomethacin.

Melatonin has a clearly more favorable side-effect profile than indomethacin. A recommended dosing strategy is to start with a bedtime dose of $3 \mathrm{mg}$ and then to increase the dose by $3 \mathrm{mg}$ every four nights until pain relief is obtained, setting $24 \mathrm{mg}$ as the upper dose limit.

However, in most cases, no treatment is necessary given that PSH has a natural course of spontaneous fluctuations, with only $14 \%$ of patients experiencing persistent symptoms [14].

\section{Conflict of interest None.}

\section{References}

1. Lansche RK (1964) Ophthmodynia periodica. Headache 4:247249

2. Sjaastad O, Egge K, Horven I, Kayed K, Lund-Roland L, Russel D, Slordahl Conradi I (1979) Chronic paroxysmal hemicranial: mechanical precipitation of attacks. Headache 19:31-36

3. Raskin NH, Schwartz RK (1980) Ice pick-like pain. Neurology 3:203-205

4. Mathew NT (1981) Indomethacin responsive headache syndromes. Headache 21:147-150

5. International Headache Society Classification Subcommittee (2004) International Classification of Headache Disorders, 2nd edn. Cephalalgia 24(Suppl.1):1-60

6. Rasmussaen BK, Jensen R, Schroll M, Olesen J (1991) Epidemiology of headache in a general population: a prevalence study. J Clin Epidemiol 44:1147-1157

7. Sjaastad O, Pettersen H, Bakketeing LS (2001) The Vågå study; epidemiology of headache I: the prevalence of ultrashort paroxysms. Cephalalgia 21:207-215

8. Pareja JA, Ruiz J, de Isla C, al-Sabbah H, Espejo J (1996) Idiopathic stabbing headache (jabs and jolts syndrome). Cephalalgia 16:93-96

9. Sjaastad O, Pettersen H, Bakketeing LS (2003) Extracephalic jabs/idiopathic stabs: Vågå study of headache epidemiology. Cephalalgia 23:50-54

10. Lance JW, Anthony M (1971) Migrainous neuralgia or cluster headache? J Neurol Sci 13:401-414

11. Piovesan EJ, Zukerman E, Kowacs PA, Werneck LC (2002) COX-2 inhibitor for the treatment of idiopathic stabbing headache secondary to cerebrovascular diseases. Cephalalgia 22:197200

12. Lance JW, Goadsby PJ (2000) Miscellaneous headaches unassociated with a structural lesion. In: Olesen J, Tfelt-Hanse P, Welch KMA (eds) The headaches. Lippincott Williams and Wilkins, Philadelphia, pp 751-768

13. Fuh JL, Kuo KH, Wang SJ (2007) Primary stabbing headache in a headache clinic. Cephalalgia 27:1005-1009

14. Selekler HM, Budak F (2004) Idiopathic stabbing headache and experimental ice cream headache (short-lived headaches). Eur Neurol 51:6-9
15. Dodick DW (2004) Indomethacin-responsive headaches syndromes. Curr Pain Headache Rep 8:19-26

16. Dodick DW (1999) Indomethacin-responsive headaches syndromes: a hypothesis on the mechanism underlying the efficacy of indomethacin in these disorders. Neurology 52:A210 (abstract)

17. Franca MC Jr, Costa AL, Maciel JA Jr (2004) Gabapentinresponsive idiopathic stabbing headache. Cephalalgia 24:993996

18. Harrigan MR, Tuteja S, Neudeck BL (1997) Indomethacin in the management of elevated intracranial pressure: a review. J Neurotrauma 14:637-650

19. Sjaastad O (1992) Cluster headache syndrome. W.B. Saunders, London

20. Martins IP, Parreira E, Costa I (1995) Extratrigeminal ice-pick status. Headache 35:107-110

21. O' Connor MB, Murphy E, Phelan MJ, Regan MJ (2008) Primary stabbing headache can be responsive to etoricoxib, a selective COX-2 inhibitor. Eur J Neurol 15:e1

22. O'Banion MK (1999) Cyclooxygenase-2: molecular biology, pharmacology, and neurobiology. Crit Rev Neurobiol 13:45-82

23. Breder CD, DeWitt D, Kraig RP (1995) Characterization of inducible cyclooxygenase in rat brain. J Comp Neurol 355:296315

24. Miettinen S, Fusco FR, Yrjänheikki J, Keinanen R, Hivronen T, Roivanen R, Nähri M, Hökfelt T, Koistinaho J (1997) Spreading depression and focal brain ischemia induce cyclooxygenase- 2 in cortical neurons through $N$-methyl-D-aspartic acid-receptors and phospholipase A2. Proc Natl Acad Sci USA 94:6500-6505

25. Dickenson AH, Chapman V, Green GM (1997) The pharmacology of excitatory and inhibitory amino acid-mediated events in the transmission and modulation of pain in the spinal cord. Gen Pharmacol 28:633-638

26. Trucco M, Antonaci F, Sandrini G (1992) Hemicrania continua: a case responsive to piroxicam-beta-cyclodextrin. Headache 32:3940

27. Peres MF, Zukerman E (2000) Hemicrania continua responsive to rofecoxib. Cephalalgia 20:130-131

28. Kromann-Andersen H, Pedersen A (1988) Reported adverse reactions to and consumption of nonsteroidal anti-inflammatory drugs in Denmark over a 17-year period. Dan Med Bull 35:187192

29. Lenzer J (2005) FDA advisers warn: COX-2 inhibitors increase risk of heart attack and stroke. BMJ 330:440

30. Hermann M, Ruschitzka F (2007) Cardiovascular risk of cyclooxygenase- 2 inhibitors and traditional non-steroidal anti-inflammatory drugs. Ann Med 39:18-27

31. Fusco C, Pisani F, Faienza C (2003) Idiopathic stabbing headache: clinical characteristic of children and adolescents. Brain Dev 25:237-240

32. Jacome DE (2001) Exploding head syndrome and idiopathic stabbing headache relieved by nifedipine. Cephalalgia 21:617618

33. Rozen TD (2003) Melatonin as a treatment for idiopathic stabbing headache. Neurology 61:865-866

34. El-Shenawy SM, Abdel-Salam OM, Baiuomy AR, El-Batran S, Arbid MS (2002) Studies on the anti-inflammatory and antinociceptive effects of melatonin in the rat. Pharmacol Res 46:235-243 